\title{
Diaza-18-crown-6 appended dual 7-hydroxyquinolines; mercury ion recognition in aqueous solution $\dagger$
}

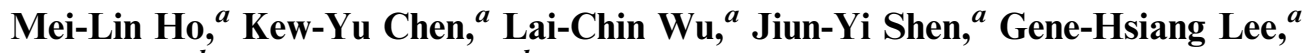 \\ Mei-Ju Ko, ${ }^{b}$ Chih-Chieh Wang, ${ }^{b}$ Jyh-Fu Lee $^{c}$ and Pi-Tai Chou ${ }^{* a}$
}

Received (in Cambridge, UK) 24th January 2008, Accepted 26th February 2008

First published as an Advance Article on the web 27th March 2008

DOI: $10.1039 / b 801366 \mathrm{~g}$

8,8'-(1,4,10,13-Tetraoxa-7,16-diazacyclooctadecane-7,16-diyl)bis(methylene)diquinolin-7-ol (TDBQ) was synthesized and proved to recognize $\mathrm{Hg}^{2+}$ via reducing $\mathrm{Hg}^{2+}$ to $\mathrm{Hg}^{+}$, forming a unique $\mathrm{Hg}_{2}{ }^{2+}-\mathrm{TDBQ}$ complex.

Mercury is considered to be one of the most serious environmental and health threats. The long atmosphere residence span of $\mathrm{Hg}^{0}$ vapour and its oxidized inorganic $\mathrm{Hg}^{2+}$ form provide facile pathways to contaminate vast amounts of water and soil. ${ }^{1}$ To date, intensive efforts have been made to develop molecular sensing systems for the mercury ion. ${ }^{2}$ Most of the detection methods have one or more limitations in terms of actual applicability, ${ }^{3}$ including interference from other metal ions, slow response to $\mathrm{Hg}^{2+}$, incompatibility with aqueous solution, low selectivity and fluorescence quenching upon $\mathrm{Hg}^{2+}$ coordination via enhanced spin-orbit coupling, energy or electron transfer. To date, the fluorescence technique offers a promising approach for simple and rapid tracking of mercury ions.

Herein, we present the facile synthesis of a novel mercury ion chemosensor based on diaza-18-crown-6 appended with dual 7-hydroxyquinoline (7HQ) groups, forming 8,8'-(1,4,10,13-tetraoxa-7,16-diazacyclooctadecane-7,16-diyl)bis(methylene)diquinolin-7-ol (TDBQ) via a Mannich type of condensation (see Scheme 1 and ESI). In this approach, diaza-crown ethers are especially focused on. ${ }^{4}$ Upon binding, the positive charge density of the metal ion leads to a reduction in electron density on the coordinating aza nitrogen atom and thereby may cause changes in the optical properties. ${ }^{5}$ Moreover, metal ion complexation abilities and selectivities of the diaza-crown can be greatly improved when ligating, proton-ionizable groups are attached to the crown ethers. ${ }^{6}$ As a strategic design, the phenolic groups and/or the pyridyl nitrogen in 7HQ may act as a sidearm to enhance the complexing ability for selected $\mathrm{f}$ metal ions. Also, the double armed diaza-crowns in TDBQ may serve as a pseudocryptand, ${ }^{4,7}$ which renders additional binding capability. This viewpoint has been supported by elegant work recently published by Farruggia et al., ${ }^{8}$ in which they applied two 8-hydroxyquino-

\footnotetext{
${ }^{a}$ Department of Chemistry and Instrumentation Center, National Taiwan University, Taipei 106, Taiwan.E-mail: chop@ntu.edu.tw

${ }^{b}$ Department of Chemistry, Soochow University, Taipei 111, Taiwan

${ }^{c}$ National Synchrotron Radiation Research Center, Hsinchu 300, Taiwan

$\dagger$ Electronic supplementary information (ESI) available: Synthetic methods, crystallographic data, XANES spectra and further experimental data. CCDC 12702. For ESI and crystallographic data in CIF or other electronic format see DOI: 10.1039/b801366g
}

lines bearing a diaza-18-crown-6 derivative binding site as a fluorescent sensor for $\mathrm{Mg}^{2+}$.

As for the signal transduction, $7 \mathrm{HQ}^{9}$ is selected mainly based on two characteristics. First, 7HQ is water soluble and is a bifunctional probe with derivatives comparable to those in many biological molecules, including DNA base units. ${ }^{9 a}$ Second, due to the unique proton tautomerization, $7 \mathrm{HQ}$ in aqueous solutions, depending on $\mathrm{pH}$, consists of four protropic equilibrium species: a normal molecule $(\mathbf{N})$, a cation $(\mathbf{C})$, an anion (A), and a zwitterion $(\mathbf{Z}){ }^{9 d}$ (See Scheme 1). Upon metal ion binding, we then expect significant spectral variation suited for signal differentiation.

As depicted in Fig. 1 (line (a)), TDBQ in $\mathrm{H}_{2} \mathrm{O}(\mathrm{pH}=7)$ revealed lower lying absorption bands at $\sim 330$ and $\sim 410 \mathrm{~nm}$, the results of which are reminiscent of normal $(\mathbf{N})$ and zwitterion (Z) species of $7 \mathrm{HQ}$, respectively, assigned in neutral water. ${ }^{9 a-c}$ Based on the spectral convolution, Mason et al. ${ }^{9 d}$ deduced the equilibrium molar percentages of $\mathbf{N}$ and $\mathbf{Z}$ species in 7 HQ to be $\sim 67 \%$ and $30 \%$, while the sum of cation $(\mathbf{C})$ and anion (A) species was estimated to be as small as $\sim 3 \%$ in neutral water. Upon adding $\mathrm{Hg}^{2+}$, the absorbance of both $\mathbf{N}$ $(330 \mathrm{~nm})$ and $\mathbf{Z}(410 \mathrm{~nm})$ tends to decrease, accompanied by a gradual increase of the anion species (A) at $358 \mathrm{~nm}$. Throughout the titration, the appearance of isosbestic points at 383 , $327,315 \mathrm{~nm}$ was observed.

The absorption spectral changes suggest that equilibrium greatly shifts from $\mathbf{N}$ and $\mathbf{Z}$ species to $\mathbf{A}$ in the presence of $\mathrm{Hg}^{2+}$. Moreover, the sigmoid plot for e.g. $358 \mathrm{~nm}$ absorbance versus $\mathrm{Hg}^{2+}$ concentration (see inset of Fig. 1) leads to a proposal of TDBQ complexation requiring a cooperative addition of two $\mathrm{Hg}^{2+} .{ }^{10 a}$ Firm support of this was provided by the Job's plot analysis, ${ }^{10 b}$ in which increases of absorbance
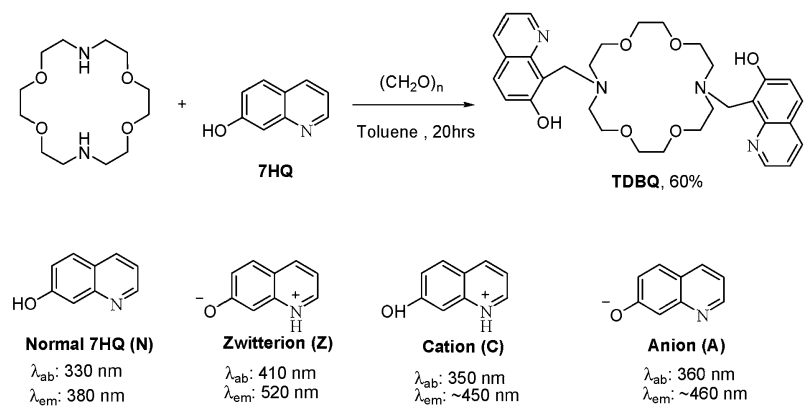

Scheme 1 (Upper) Synthetic scheme of TDBQ. (Lower) Various equilibrium species of 7HQ in aqueous solution and their corresponding absorption and emission maxima. 


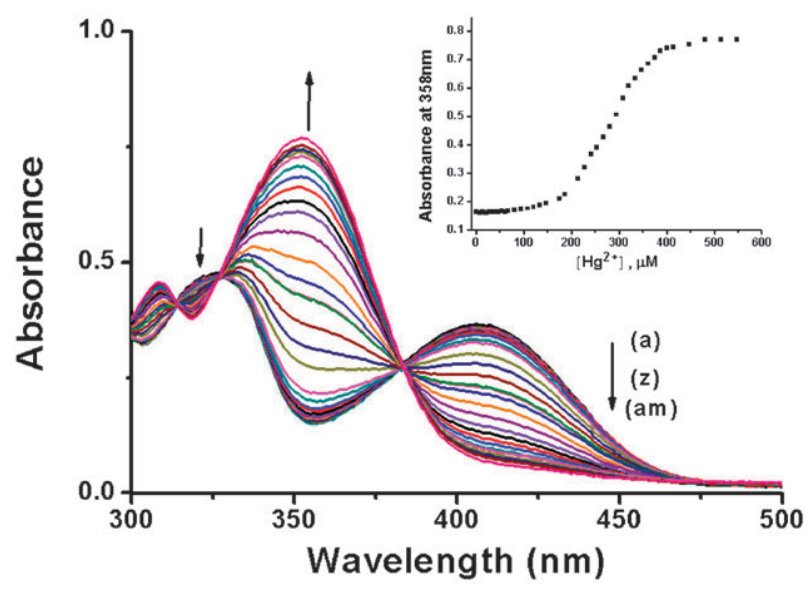

Fig. 1 Absorption spectra of TDBQ $(7.8 \mu \mathrm{M})$ in $\mathrm{H}_{2} \mathrm{O}(\mathrm{a}, \mathrm{pH}=7)$ upon addition of $\mathrm{Hg}^{2+}$ in an increment of $6.7 \mu \mathrm{M}(\mathrm{b}-\mathrm{k})$, followed by $13.3 \mu \mathrm{M}(1-\mathrm{z}), 33.4 \mu \mathrm{M}$ (ai-am). Inset: Absorbance at $358 \mathrm{~nm}$ against $\left[\mathrm{Hg}^{2+}\right]$.

at e.g. $358 \mathrm{~nm}$ were plotted against molar fractions of TDBQ and $\mathrm{Hg}^{2+}$ under the condition of a constant total concentration. As such, the concentration of TDBQ- $\mathrm{Hg}^{2+}$ reached a turning point when the molar fraction of $\left[\mathrm{Hg}^{2+}\right] /\left(\left[\mathrm{Hg}^{2+}\right]+\right.$ [TDBQ]) was about 0.6 (Fig. 2A), indicating a stoichiometry of $2\left(\mathrm{Hg}^{2+}\right)$ : 1 (TDBQ) for the association.

A direct, firm evidence of the stoichiometry of complexation perhaps relies on the structural identification. In this approach, a single crystal was successfully obtained from a slow diffusion of $\mathrm{MeOH}$ into a water solution of either $\mathrm{Hg}^{2+}$ free TDBQ or a $1: 2$ mixture of TDBQ and $\mathrm{Hg}\left(\mathrm{ClO}_{4}\right)_{2} \cdot x \mathrm{H}_{2} \mathrm{O}$. As shown in Fig. S5(a) (ESI), the molecular structure of TDBQ reveals a pocket-like geometric conformation due to the hydrogen bond interaction between the hydroxyl group $(\mathrm{O}(11)-\mathrm{H}(11)$ of $7 \mathrm{HQ}$ and nitrogen atom $(\mathrm{N}(1))$ of the macrocycle with an $\mathrm{O}(11)-\mathrm{N}(1)$ distance of $2.683 \AA$ A. Upon addition of $\mathrm{Hg}^{2+}$, TDBQ also forms a pocketlike geometric conformation (Fig. S5(b)), in which two mercury cations are trapped by the macrocycle, mainly due to the coordination of mercury ions $(\mathrm{Hg}(1)$ and $\mathrm{Hg}(2))$ with two nitrogen atoms $(\mathrm{N}(1)$ and $\mathrm{N}(2))$, two oxygen atoms $(\mathrm{O}(1)$ and

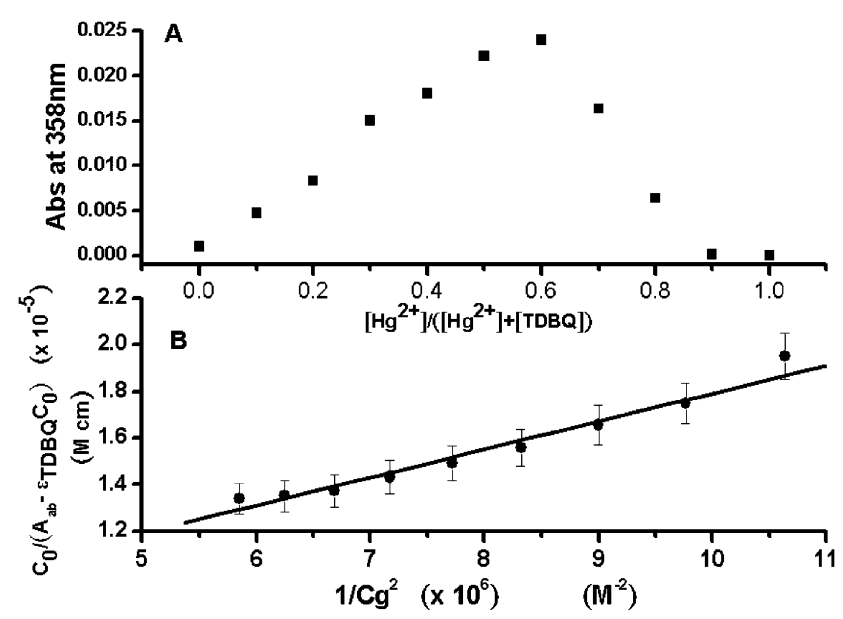

Fig. 2 (A) The increase of absorption at $358 \mathrm{~nm}$ was plotted against the mole fraction of $\mathrm{Hg}^{2+}$ (Job's plot). [TDBQ] $+\left[\mathrm{Hg}^{2+}\right]=7.0 \mu \mathrm{M}$. (B) The plot of $C_{0} /\left(A_{\mathrm{ab}}-\varepsilon_{\mathbf{T D B Q}} C_{0}\right)$ against $1 / C_{\mathrm{g}}{ }^{2}$ at $358 \mathrm{~nm}$ (see text).
$\mathrm{O}(3)$ ) of the macrocycle and nitrogen atoms (N(3), N(4)) of 7HQ. In a qualitative manner, the motion of TDBQ to recognize mercury ion resembles the Sensitive Plant. In other words, TDBQ is able to pinch and form a cavity suitable for accommodating dual mercury ions.

As depicted in Fig. S5(b), the nitrogen of 7HQ also donates a lone-pair electron to the mercury ion, facilitating the complex formation. The selected bond lengths around the $\mathrm{Hg}(1)$ and $\mathrm{Hg}(2)$ atoms are given in Table S1 (see ESI). Surprisingly, the $\mathrm{Hg}(1)-\mathrm{Hg}(2)$ distance of 2.5207(3) $\AA$ is significantly shorter than $\mathrm{Hg}-\mathrm{Hg}$ distances of 2.7362(6), 2.6881(4), and 2.5469(8) $\AA$ reported in $\left[\mathrm{Pt}_{2} \mathrm{Hg}_{2}\left(\mathrm{P}_{2} \text { phen }\right)_{3}\right]\left(\mathrm{PF}_{6}\right)_{2},\left[\mathrm{Pd}_{2} \mathrm{Hg}_{2}\left(\mathrm{P}_{2} \text { phen }\right)_{3}\right]\left(\mathrm{PF}_{6}\right)_{2}$, and $\left[\mathrm{Hg}_{2}(\mathrm{TLA})_{2}\right]\left(\mathrm{ClO}_{4}\right)_{2}$, respectively, ${ }^{11 a, b}$ however, it is comparable with that of $2.5358(8) \AA$ in $\left[\mathrm{Hg}_{2}\left(\mathrm{C}_{36} \mathrm{H}_{46} \mathrm{~N}_{6} \mathrm{Se}_{2}\right)\right]\left(\mathrm{PF}_{6}\right)_{2}{ }^{11 c}$ It is also noteworthy that the bond length for $\mathrm{Hg}_{2}{ }^{2+}$ is 2.524(2) $\AA$ in water. ${ }^{11 d}$ The result indicates the sum of charges for two mercury ions to be +2 in the crystal.

To provide another evidence of the charge of mercury ion in the solid crystal, XANES measurement was performed at $\mathrm{Hg}$ $\mathrm{L}_{\mathrm{III}}$-edge of the corresponding crystal. For comparison, spectra of $\mathrm{HgCl}_{2}$ and $\mathrm{Hg}_{2} \mathrm{Cl}_{2}$ are also shown in Fig. S6 (see ESI). According to the electric-dipole selection rules, the spectral region from $12280-12295 \mathrm{eV}$ is assigned to the transition of $2 \mathrm{p}_{3 / 2} \rightarrow 6 \mathrm{~s},{ }^{12}$ while those of $>12295 \mathrm{eV}$ are attributed to the transitions of $2 \mathrm{p}_{3 / 2} \rightarrow 6 \mathrm{~d} . \mathrm{Hg}^{2+}$ exhibits an obvious peak at $12285 \mathrm{eV}$, which apparently is lacking at the same energy for $\mathrm{Hg}^{+}$. This is due to the fact that $\mathrm{Hg}^{2+}$ has a higher density of the empty 6s electronic state than that of $\mathrm{Hg}^{+}$. The XANES spectrum of the prepared TDBQ-mercury crystal resembles that of the reference $\mathrm{Hg}^{+}$, indicating that the oxidation state of the crystal is best described as $\mathrm{Hg}^{+}$.

The reduction of $\mathrm{Hg}^{2+}$ has been observed in the structural characterization of a $\mathrm{Hg}_{2}{ }^{2+}$ complex containing a tripodal nitrogen ligand. ${ }^{11 b, 13}$ It is plausible that $\mathrm{Hg}^{2+}$ would be reduced to $\mathrm{Hg}^{+}$under the tripodal nitrogen ligands, i.e. diazacyclooctadecane in TDBQ, containing solution. The reduction of $\mathrm{Hg}^{2+}$ may be facilitated by $\mathrm{Hg}(\mathrm{I})-\mathrm{Hg}(\mathrm{I})$ bonding formation in combination with further stabilization by diazacyclooctadecane complexation, forming a stable $\mathrm{Hg}_{2}{ }^{2+}-\mathbf{T D B Q}$ complex. This may lead to a positive reduction potential, which is large enough to have overall negative changes of $\Delta G$ upon coupling with e.g. oxidation of water. Nevertheless, full decipherment of the actual redox mechanism is still pending resolution.

On the above basis, thermodynamic parameters such as the association constant of the complexation can be deduced via the, relationship of absorbance, $A_{\mathrm{ab}}$, versus added $\mathrm{Hg}^{2+}$ concentration $\left(C_{\mathrm{g}}\right)$ expressed in eqn (1) (also see ESI for detailed derivation)

$$
\begin{aligned}
\frac{C_{0}}{A_{\mathrm{ab}}-\varepsilon_{\mathbf{T D B Q}} C_{0}}= & {\left[\frac{1}{K_{a}\left(\varepsilon_{\mathbf{T D B Q}-\mathrm{Hg}^{+}}-\varepsilon_{\mathbf{T D B Q}}\right)}\right] \frac{1}{C_{\mathrm{g}}^{2}} } \\
& +\frac{1}{\varepsilon_{\mathrm{TDBQ}-\mathrm{Hg}^{+}}-\varepsilon_{\mathbf{T D B Q}}}
\end{aligned}
$$

where $C_{0}$ denotes the initially prepared concentration of TDBQ, $\varepsilon_{\mathbf{T D B Q}}\left(\sim 2.1 \times 10^{4} \mathrm{M}^{-1} \mathrm{~cm}^{-1}\right)$ is the molar extinction coefficient of TDBQ (A) at peak wavelength of $358 \mathrm{~nm}$. As a result, a straight line plot of $C_{0} /\left(A_{\mathrm{ab}}-\varepsilon_{\mathbf{T D B Q}} C_{0}\right)$ versus TDBQ $/\left[\mathrm{Hg}^{2+}\right]^{2}$ (see Fig. 2B) supports the proposal of 


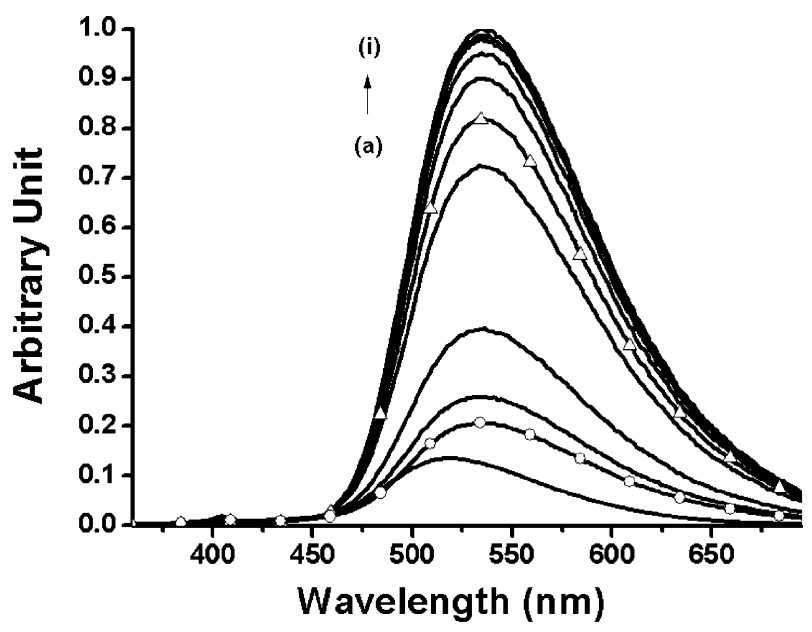

Fig. 3 Emission spectra of TDBQ $\left(7.8 \mu \mathrm{M}\right.$ in $\left.\mathrm{H}_{2} \mathrm{O}, \mathrm{pH}=7\right)$ upon addition of $\mathrm{Hg}^{2+}$ in an increment of $133.3 \mu \mathrm{M}(\mathrm{a}-\mathrm{b})$, followed by $33.3 \mu \mathrm{M}(\mathrm{c}-\mathrm{i}), \lambda_{\mathrm{ex}}=358 \mathrm{~nm}$; (j) (- $\left.\bigcirc-\right)$ The addition of $1 \mathrm{mM}$ DMPS on (i). (k) (- $\triangle-)$ The addition of $1.5 \mathrm{mM}\left[\mathrm{Hg}^{2+}\right]$ on (j). $\lambda_{\mathrm{ex}}=358 \mathrm{~nm}$.

$\mathrm{Hg}_{2}{ }^{2+}$ for the complexation. The association constant $K_{\mathrm{a}}$ was then deduced to be $4.47 \times 10^{6} \mathrm{M}^{-2}$ from the quotient of intercept divided by the slope.

As for the fluorescence titration, the excitation of $\mathrm{Hg}^{2+}$ free TDBQ at e.g. $358 \mathrm{~nm}$ leads to a zwitterion-like (Z) emission maximized at $\sim 517 \mathrm{~nm}$. Upon addition of $\left[\mathrm{Hg}^{2+}\right]$, the $358 \mathrm{~nm}$ excitation, which is the peak wavelength of the TDBQ anion species incorporating $\mathrm{Hg}_{2}{ }^{2+}$, rendered an increase of the emission band with peak wavelength at $527 \mathrm{~nm}$ (see Fig. 3). The lack of $7 \mathrm{HQ}$-anion-like $450 \mathrm{~nm}$ emission $^{9 d}$ leads us to propose that the $\mathrm{Hg}_{2}{ }^{2+}$ incorporated TDBQ anion species undergo excited-state charge transfer from phenolic (HOMO) to the pyridyl (LUMO) moiety, ${ }^{14}$ resulting in strengthening of the pyridyl- $\mathrm{Hg}_{2}{ }^{2+}$ dative bond. The net result resembles a zwitterion-like structure (see Scheme 1) that gives rise to the $527 \mathrm{~nm}$ emission similar to that of the $\mathbf{Z}$ form of $7 \mathrm{HQ} .{ }^{14}$ Note the emission intensity increases by $\sim$ one order of magnitude during the titration (see Fig. 3). Based on emission spectra, the reversibility of the recognition process was performed by adding mercury chelating agents, sodium 2,3dimercapto-1-propanesulfonate (DMPS). As shown in Fig. 3, after addition of $1 \mathrm{mM}$ DMPS into the solution containing TDBQ and mercury ion, the zwitterion $(\mathbf{Z})$ emission intensity decreased by $\sim 5$ fold. Subsequently, adding $1.5 \mathrm{mM} \mathrm{Hg}\left(\mathrm{ClO}_{4}\right)_{2}$ leads to the increase of the emission back to $\sim 80 \%$ of the original intensity, revealing its good reversibility.

To probe the $\mathrm{Hg}_{2}{ }^{2+}-\mathbf{T D B Q}$ complex stability as a function of $\mathrm{pH}$, the absorption spectrum of a solution containing TDBQ and $\mathrm{Hg}^{2+}$ in equimolar amounts $(1.5 \mu \mathrm{M})$ at various $\mathrm{pH}$ values was constructed (see Fig. S7 in ESI). For comparison, acid-base absorption titration of TDBQ was also performed. The results of TDBQ showed that $\mathrm{p} K_{\mathrm{a}}$ values for the deprotonation of the nitrogen atom and of the hydroxyl groups in $\mathrm{H}_{2} \mathrm{O}$ were 5.5 and 9.2, respectively. For $\mathrm{Hg}_{2}{ }^{2+}-\mathbf{T D B Q}$, the second deprotonation process $\left(\mathrm{p} K_{\mathrm{a}} \sim 8.2\right)$ shifted to lower $\mathrm{pH}$ values than the first one. This change in $\mathrm{p} K_{\mathrm{a}}$ was presumably caused by chelation of mercury ion with the phenolic oxygen. Deprotonation of both phenol groups on TDBQ associated with $\mathrm{Hg}_{2}{ }^{2+}$ yielded a neutral complex. This neutral complex with $\mathrm{Hg}^{2+}$ was formed at $\mathrm{pH}$ values higher than 7. Similar results have been reported in the structural characterization of diaza-18-crown-6 appended with two 5-chloro-8-hydroxyquinoline-7-yl groups, the effective chemosensors for $\mathrm{Mg}^{2+}$ or $\mathrm{Hg}^{2+} .8,15$

Finally, competitive experiments have been performed and the results are depicted in Fig. S8 (ESI). In this experiment, $1 \mu \mathrm{M}$ solution of TDBQ was tested in the presence of other metal cations, including alkali, alkaline earth metals and certain heavy metals. As shown by the enhancement of emission intensity after adding equal molar $\mathrm{Hg}^{2+}$ with respect to the competing metal ions (Fig. S8), TDBQ seems to retain moderate selectivity for $\mathrm{Hg}^{2+}$ in the presence of a range of competing ions found in environmental and biological settings.

In conclusion, TDBQ achieves $\mathrm{Hg}^{2+}$ recognition via the reduction of $\mathrm{Hg}^{2+}$, forming a $\mathrm{Hg}_{2}{ }^{2+}-$ TDBQ complex. In this approach, two 7HQ moieties not only act as dual sidearms attached to diaza-18-crown-6, forming pseudo-cryptand that greatly enhances the binding strength, but also serve as a signal transducer. Single crystals of TDBQ-mercury complex have unambiguously resolved a dinuclear $(\mathrm{Hg})$ center with $\mathrm{Hg}_{2}{ }^{2+}$ formation that is unique among numerous approaches for sensing mercury ion.

\section{Notes and references}

1 D. W. Boening, Chemosphere, 2000, 40, 1335.

2 (a) X.-J. Zhu, S.-T. Fu, W.-K. Wong, J.-P. Guo and W.-Y. Wong, Angew. Chem., Int. Ed., 2006, 45, 3150; (b) A. Ben Othman, J. W. Lee, J. S. Wu, J. S. Kim, R. Abidi, P. Thuéry, J. M. Strub, A. Van Dorsselaer and J. Vicens, J. Org. Chem., 2007, 72, 7634; (c) S. Yoon, E. W. Miller, Q. He, P. H. Do and C. J. Chang, Angew. Chem., Int. Ed., 2007, 46, 6658; (d) J. Liu and Y. Lu, Angew. Chem., Int. Ed., 2007, 46, 7587; (e) Y. Che, X. Yang and L. Zang, Chem. Commun., 2008, 1413.

3 (a) S. Yoon, A. E. Albers, A. P. Wong and C. J. Chang, J. Am. Chem. Soc., 2005, 127, 16030; (b) E. M. Nolan, M. E. Racine and S. J. Lippard, Inorg. Chem., 2006, 45, 2742.

4 K.-W. Chi, K. T. Shim, H. Huh, U. Lee and Y. J. Park, Bull. Korean Chem. Soc., 2005, 26, 393.

5 K. C. Song, J. S. Kim, S. M. Park, K. C. Chung, S. Ahn and S. K. Chang, Org. Lett., 2006, 8, 3413.

6 M. Pietraszkiewicz, R. Gasiorowski and Z. Brzózka, J. Inclusion Phenom. Mol. Recognit. Chem., 1990, 9, 259.

7 N. Su, J. S. Bradshaw, X. X. Zhang, H. Song, P. B. Savage, G. Xue, K. E. Krakowiak and R. M. Izatt, J. Org. Chem., 1999, 64, 8855.

8 G. Farruggia, S. Iotti, L. Prodi, M. Montalti, N. Zaccheroni, P. B. Savage, V. Trapani, P. Sale and F. I. Wolf, J. Am. Chem. Soc., 2006, 128, 344.

9 (a) G. Angulo, J. A. Organero, M. A. Carranza and A. Douhal, $J$. Phys. Chem. B, 2006, 110, 24231; (b) C. Manca, C. Tanner and S. Leutwyler, Int. Rev. Phys. Chem., 2005, 24, 457; (c) S.-I. Lee and D.-J. Jang, J. Phys. Chem., 1995, 99, 7537; (d) S. F. Mason, J. Philp and B. E. Smith, J. Chem. Soc. A, 1968, 3051.

10 (a) S. Auparakkitanon, S. Chapoomram, K. Kuaha, T. Chirachariyavej and P. Wilairat, Antimicrob. Agents Chemother., 2006, 50(6), 2197, and references therein; (b) K. A. Connors, Binding Constants, 1987, Wiley, New York.

11 (a) V. J. Catalano, M. A. Malwitz and B. C. Noll, Inorg. Chem., 2002, 41, 6553; (b) D. C. Bebout, J. F. Bush, E. M. Shumann, J. A. Viehweg, M. E. Kastner, D. A. Parrish and S. M. Baldwin, J. Chem. Crystallogr., 2003, 33, 457; (c) S. Panda, H. B. Singh and R. J. Butcher, Inorg. Chem., 2004, 43, 8532; (d) J. Rosdahl, I. Persson, L. Kloo and K. Ståhl, Inorg. Chim. Acta, 2004, 357, 2624.

12 F. Studer, D. Pelloquin, A. Maignan, C. Michel, M. Hervieu and B. Raveau, Physica C, 1995, 242, 1.

13 M. Kadarkaraisamy and A. G. Sykes, Polyhedron, 2007, 26, 1323.

14 P.-T. Chou, C.-Y. Wei, C.-R. C. Wang, F.-T. Hung and C.-P. Chang, J. Phys. Chem. A, 1999, 103, 1939.

15 L. Prodi, C. Bargossi, M. Montalti, N. Zaccheroni, N. Su, J. S. Bradshaw, R. M. Izatt and P. B. Savage, J. Am. Chem. Soc., 2000, 122, 6769 . 